\title{
AC 2009-234: TRIBULATIONS OF A NEW ELECTRICAL ENGINEERING PROGRAM: FROM PROGRAM INCEPTION TO ABET ACCREDITATION
}

\section{Esteban Rodriguez-Marek, Eastern Washington University}

ESTEBAN RODRIGUEZ-MAREK is an Associate Professor in the department of Engineering and Design at Eastern Washington University. He did his graduate work in Electrical Engineering at Washington State University. He worked as a research scientist at Fast Search \& Transfer before transferring to the Department of Engineering \& Design at Eastern Washington University. His interest include image and video processing, communication systems, digital signal processing, and cryptographic theory and applications.

\section{Min-Sung Koh, Eastern Washington University}

\section{Michael Brzoska, Eastern Washington University}

Dr. Michael Brzoska holds a PhD in Mechanical Engineering. He is a Professor and the Associate Dean of Computing and Engineering Sciences at Eastern Washington University. He is an active member of ASME and coordinates the annual Symposium on Applications in Computer Fluid Dynamics.

\section{Claudio Talarico, Eastern Washington University}

Claudio Talarico is an Assistant Professor of Electrical Engineering at Eastern Washington University. Before joining Eastern Washington University, he worked at University of Arizona, University of Hawaii and in industry, where he held both engineering and management positions at Infineon Technologies, IKOS Systems (now Mentor Graphics), and Marconi Communications. His research interests include design methodologies for integrated circuits and systems with emphasis on system-level design, embedded systems, HW/SW co-design, system specification languages, and early design assessment, analysis, and refinement of complex SOCs. Talarico received a PhD in electrical engineering form the University of Hawaii at Manoa, and is a member of IEEE. Contact him at ctalarico@ewu.edu 


\title{
Tribulations of a New Electrical Engineering Program: From Program Inception to ABET Accreditation
}

\begin{abstract}
In the Fall of 2002, Eastern Washington University (EWU) received a call from the American Electronics Association (AeA) requesting our institution to initiate the process to open an Electrical Engineering program to fill an existing gap in the State's labor force. The fact that our Department was exclusively dedicated to Engineering Technology put to the offer an even more exciting overtone, as we knew that it would not only be challenging, but that we would be walking on what for us was uncharted territory. On hindsight, the best thing that our Department had going in our favor is lacking the vision to anticipate the many hurdles that we would encounter. The first of these hurdles came in the form of state legislation. The State of Washington has a provision in its laws that precludes public comprehensive universities from offering engineering degrees, this privilege being reserved to public research institutions. After innumerable visits to the state capital and irrefutable evidence of the need for more electrical engineers in the state, the law was overturned, although only for Electrical Engineering. But the problems were just starting. We knew we had ahead of us a monumental competitor in the Higher Education Coordinating Board, an organization that rules and regulates approval of new programs in the State, but what we did not know is that fierce enemies would rise from within. The prospect of a new program, potentially very costly for the University, incited several programs at EWU to protest against the opening of an Electrical Engineering degree. Great temple and adroit political maneuvering by the administration, which was fully behind the new program, were required for the eventual internal approval of the degree. And the Higher Education Coordinating Board was still to come! This paper describes the trials and tribulations that were overcome by the Department of Engineering \& Design from the initial idea to the final accreditation by the Accreditation Board for Engineering and Technology (ABET) [1] in the summer of 2008.
\end{abstract}

\section{Introduction}

It is not every day that a new Electrical Engineering program is started. This is an unfortunate fact for at least a couple of reasons. First, there is a severe need for more electrical engineers in the workforce, as a large percentage of the baby boomers are set to retire in the next few years. Second, the lack of new programs leads to very little literature being available to universities trying to start their own program, and when available, it may not address issues faced by a given institution [2][3][4][5][6]. While the overarching goal of EWU was to address the first reason mentioned above, the goal of this paper is to continue filling in the vacuum in the literature. The paper will describe the path taken by the University in the conception, design and implementation of the program. Section II talks briefly about the history of the program, followed by curriculum development in Section III. Section IV describes the Capstone Design class used in the curriculum, a multidisciplinary design class that has enjoyed a big success with the student population. The steps taken to prepare for the visitation of the ABET accreditation 
team are detailed in Section V, and conclusions and a summary of the various lessons learned through the process are presented in Section VI.

\section{History of the Program}

The Electrical Engineering degree is housed by the Department of Engineering \& Design (E\&D) at EWU. EWU is a midsize regional comprehensive university based 15 miles from the metropolitan area of Spokane, which has roughly 400,000 habitants. Spokane has another university offering electrical engineering, a prestigious but expensive private institution. A land grant, research state university is located 75 miles South. EWU has a history typical of universities of this size: it was founded over 120 years ago as a normal school. The roots of the department extend to one of the original university departments, "Manual Arts" around the turn of the previous century. Its name progressed through many iterations: Practical Arts, Industrial and Practical Arts ('40s/'50s), Industrial Education and Technology ('60s), Technology('80s), Engineering Technology and Multimedia Design('90s), and finally, Engineering and Design('00s). The various department names indicate an evolution in department offerings.

In the late ' 80 s the engineering technology programs were initiated with the Computer Engineering Technology and Mechanical Engineering Technology programs. For many years these programs grew and adapted to the various changes in the industry, but were left otherwise unchanged. A wave of retirements in the early 2000s filled the department with new blood in the Computer Engineering Technology program.

While this was happening at EWU, reports of severe need for engineers started appearing in the media. These reports resulted in a task force being formed by the Washington Council of the American Electronics Association. The task force concluded that "...the cure is to train more people...[where] the need is especially acute in engineering, computer science, informational systems and related technology fields." Further, the AeA task force advised that "state colleges and universities must increase capacity and improve access for would-be students" and that "Governor Locke and the legislature should focus on funding new capacity in higher education." The Washington State Higher Education Coordinating Board, in its Master Plan 2000, acted on this advice and stated its number one investment strategy to be "adding capacity in instruction, instructional support, and research space needed to implement the master plan initiatives for enrollment growth in high-demand fields."

EWU saw itself in the unique position of being poised to meet the demands of industry, follow the recommendations of the AeA task force, and provide the additional capacity called for by the Higher Education Coordinating Board and Governor Locke. In addition, the College of Science, Mathematics and Technology at EWU began a process of reorganizing and redeveloping the programs in its departments of Engineering Technology and Multimedia Design, Computer Science and Physics in response to the current workforce needs particularly as they applied to the regional technology sector. To this end, the faculties of these departments united within a new

academic unit named the School of Computing and Engineering Sciences where interdependent programs can focus on student learning within the context of the ever-increasing demand for 
technology connected degrees. Seeing the benefit of a new academic unit at EWU, the Washington State legislature funded the design of a new state-of-the-art building to house the school and its programs.

In a unique arrangement, the State paid for the design and construction of the building and EWU agreed to purchase the equipment through individual and company gifts and donations, equipment vender discounts, federal appropriations, grants, and foundation support. In the end, the university raised $\$ 6$ million dollars in equipment funds. The sources included two large federal appropriations, several large foundation grants, many individual contributions, and much company support including large equipment donations and significant monetary support.

With the advent of the new facilities, AeA approached EWU about filling a crucial need for electrical engineers in the State. After reviewing the Department of Engineering Technology and Multimedia Design's curriculum, faculty, and facilities, it was decided that with the newly constructed engineering facilities would be more than adequate to house a BSEE program. Further, it was decided that since there was more demand for electrical engineers in the west side of the state, this should be the first location of the program. Then, later the program would be offered on the east side of the state on EWU's main campus. The North Seattle Community College (NSCC) campus was selected for the site for the new program as it already had large well equipped but underutilized electronics laboratories which housed an existing AS degree in electronics. The laboratories appeared to be generally adequate to offer a BSEE program. A pre-engineering program had existed there for many years as well.

In order for a regional university like EWU to offer a BSEE program Washington State law had to be revised. Organized by EWU, NSCC, AeA and many engineering firms, state representatives and senators were persuaded to put forward legislation to amend the state law allowing regional universities to offer the BSEE program. There was some initial apprehension by representatives and senators about universities other than R-1 research universities offering engineering programs. In the end, the bills put forward were passed by both houses and signed into law in 2003 by Governor Locke.

Next, the Higher Education Coordinating Board which must approve all new programs had to be approached. A lengthy request was prepared that discussed all program aspects. Again, there was much apprehension concerning non R-1 research universities teaching engineering, the impact the new program would have on private universities throughout the state, and a new program first beginning offered on a branch campus site. We were able to convince the HECB on the first issue, somewhat convince them on the second issue but on the third we were provided some requirements that had to be met. EWU was required to establish a program on the main campus prior to offering a program on the west side of the state. Other HECB requirements included achieving accreditation, maintaining a maximum student faculty ratio of $18 / 1$ and being able to report back to the HECB within a year that the program was a success. Further, as a result of negotiations between a local private university president and EWU president, we were required to delay the starting date by one year to 2005. The struggle through the HECB took over a year with multiple meetings and endless requests for more information. 
Since the program could not result in additional state spending, the operating money had to come out of the existing EWU budget (an internal relocation). Many on campus were furious and, of course, the BSEE program had to be approved by faculty committees. The administration was extremely supportive of the BSEE effort and in the end EWU faculty committees did approve the new program. Luckily, the HECB created opportunities for "high demand" fields to receive additional funding. This resulted in three new department faculty positions. Therefore, internal relocations were kept to a minimum.

\section{Curriculum Development}

The most important step in the planning of the electrical engineering degree was, obviously, the curriculum. Before getting down to the actual four year plan, the Department sought help from its various constituencies, such as the advisory board, potential employers and electrical engineering faculty in other universities. A focus group within the advisory board, mainly containing representatives from regional industries, was conducted early in the process. The focus group was geared toward determining the trends in industry in the region, as well as obtaining input on what the ideal graduate from EWU would look like. Similar input was sought from several potential employers in the State. Phone conversations, e-mails and written correspondence were used to acquire data from companies hiring engineers.

Feedback from various comparable university faculty, both in the area and from the Northwest in general, was received in the form of written correspondence. The purpose of this exercise was to generalize the trends observed from the focus group within the advisory board and from the potential employers' data. Furthermore, input was requested on specific advice on sustainable management of classroom growth, i.e. where to cap enrollment, laboratory design, etc.

The final constituency whose input was used was the faculty body itself. After all, we would be teaching the classes. Out of all of this information we observed that there were commonalities that needed to be addressed. First, the job of an engineer in the $21^{\text {st }}$ century requires a vast set of skills beyond that of plain technical expertise. In order to succeed, a graduate should have excellent communications skills, both written and oral. For instance, consider the hypothetical situation of an engineer that designs a product and wants to commercialize it. The engineer first has to find investors that will be interested in injecting funds into the project. To do this the prototype not only needs to be in adequate working condition, but its needs to be "sold" to investors in a manner that it will be attractive and seducing, most likely through an oral presentation. Once the funding has been secured, progress reports and progress presentation must be done regularly to ensure that the venture capitalists can see their investments have been put to good use and are en route to timely production. Finally, once the product is on the market, tweaks must be done to customize the product for particular clients. This customization requires clear, concise and unambiguous two-way interaction with the client. From this simple example it was made obvious that efforts had to be made to ensure EWU graduates had significant exposure to various means of communication, such as written lab and project reports, oral presentations, critiques, etc. 
The ability to communicate well was purported as one of the most important skills a graduate needed to have, but it was observed that other skills had to be coupled to it to exploit it to its full potential, namely, leadership skills, the ability to work well in teams and a broad interaction with other disciplines. Among the other important observations from the various constituencies input was the necessity to make the student's transition into the labor marked as seamless as possible, i.e. attempt to reduce the shock that students go through when leaving the academic world and entering the workforce.

As a result of these observations, the decision was taken to include a significant laboratory component into the curriculum, possibly manifesting itself in open ended problems used as endof-term projects and, whenever possible, having a multidisciplinary component. The final decision, and one that played a significant role in the Higher Education Coordinating Board granting final approval for the program, was to include a laboratory component to each and every class in the curriculum ${ }^{1}$. The laboratory component typically involves lab exercises, in which the student gets exposed to various measurement equipment and techniques, modeling languages, and design methodology. However, to ensure that students also have experience in solving real engineering problems, the curriculum is designed so that at least in one class per quarter the student is exposed to an open ended design experience. Faculty have noticed that the implementation of this open-ended problem requirement has increased both the student's ability to understand the material and their dedication and interest in the class. Moreover, implementation, coupled with design, exposes the student to several problems that typically arise in the industrial setting, thus providing a system-level, critical perspective to design and analysis. Sample problems used as projects in classes of various academic levels are listed next: digital audio watermarking, interactive edge detection systems, low-density parity-check error correction simulation system, Simulink implementation of quadrature amplitude modulation, quadrature phase shift keying system implementation on a DSP board, solution to obtaining a tapping signal from miners trapped underground using seismic sensors, FPGA implementation of UART, implementation of fingerprint identification system, design and implementation of autonomous robot navigating itself out of a maze, heating and ventilation air conditioning system control, microcontroller implementation of high frequency meter, modeling of a microcontrollerbased light seeking solar panel, fault current analysis for power distribution system, identifying and modeling losses for Avista's power distribution system, etc. Note that some of the problems were obtained from industrial partners, although many projects are the result of students' own initiative. Realistic constraints beyond technical ones are addressed as well, as the table shown in Figure 1 must be completed and turned in with the project final report. Further, a portion of the grade is dedicated entirely to the addressing of realistic constraints.

\footnotetext{
${ }^{1}$ There is one exception to this rule. The freshman level introduction to digital circuits class does not have a laboratory component, because this class also serves as a supporting class for the Computer Science Department, which was adamant about its students not requiring the laboratory component of the class. To overcome the problem, Intro to Digital Circuits is followed by a laboratory-intensive class, Digital Hardware. This system seems to have met the needs of both departments.
} 
Figure 1. Sample table to be used for assessing student exposure to realistic constraints.

\begin{tabular}{|c|c|c|c|c|}
\hline \multirow[t]{2}{*}{ Constraint } & \multicolumn{4}{|c|}{$\begin{array}{l}\text { Level of Coverage of } \\
\text { Constraint }\end{array}$} \\
\hline & High & Medium & Low & N/A \\
\hline \multicolumn{5}{|l|}{$\begin{array}{l}\text { Functional constraints: } \\
\text { (geometry, motion of parts, forces involved, energy needed, } \\
\text { materials to be used, control system, and information flow) }\end{array}$} \\
\hline \multicolumn{5}{|l|}{$\begin{array}{l}\text { Safety constraints: } \\
\text { (operational, and human) }\end{array}$} \\
\hline \multicolumn{5}{|l|}{$\begin{array}{l}\text { Quality constraints: } \\
\text { (regulations, standards, codes, inspection, testing, labeling, } \\
\text { and reliability) }\end{array}$} \\
\hline \multicolumn{5}{|l|}{$\begin{array}{l}\text { Manufacturing constraints: } \\
\text { (factory limitations, means of production, wastes, supplier } \\
\text { quality, installation, assembly, and part clearance) }\end{array}$} \\
\hline \multicolumn{5}{|l|}{$\begin{array}{l}\text { Timing constraints: } \\
\text { (schedule, project planning, project control, design detailing, } \\
\text { compliance tests, supply chains, delivery schedule, and } \\
\text { distribution networks) }\end{array}$} \\
\hline \multicolumn{5}{|l|}{$\begin{array}{l}\text { Economic constraints: } \\
\text { (size of market, market segments, supplier costs, testing } \\
\text { costs, tooling costs, labor, overhead, assembly costs, } \\
\text { inspection costs, spare parts cost, warranty costs, time value } \\
\text { of money, capital costs, machine costs, and material costs) }\end{array}$} \\
\hline \multicolumn{5}{|l|}{$\begin{array}{l}\text { Ergonomic constraints: } \\
\text { (user needs, type of operation, instructions, warnings, man- } \\
\text { machine relationships, operation, controls, layout, clarity, and } \\
\text { interactions) }\end{array}$} \\
\hline \multicolumn{5}{|l|}{$\begin{array}{l}\text { Ecological constraints: } \\
\text { (impact on natural resources, social resources, political } \\
\text { consequences, commercial consequences, implications for } \\
\text { following generations, noise, radiation, and disposal) }\end{array}$} \\
\hline \multicolumn{5}{|l|}{$\begin{array}{l}\text { Aesthetic constraints: } \\
\text { (customer appeal, shape, color, customer delight, culture, } \\
\text { history, trends, rate of change of technology, and product } \\
\text { families) }\end{array}$} \\
\hline \multicolumn{5}{|l|}{$\begin{array}{l}\text { Life-cycle constraints: } \\
\text { (product life, wear, special uses, working environments, } \\
\text { maintenance, regulations, service intervals, exchange and } \\
\text { repair, cleaning, diagnostics, recycleability, and scrap) }\end{array}$} \\
\hline \multicolumn{5}{|l|}{$\begin{array}{l}\text { Ethical constraints: } \\
\text { (public safety, health, welfare, and integrity) }\end{array}$} \\
\hline \multicolumn{5}{|l|}{$\begin{array}{l}\text { Legal constraints: } \\
\text { (government regulations, private regulations, public safety, } \\
\text { patents, trademarks, and copyrights) }\end{array}$} \\
\hline $\begin{array}{l}\text { Note: You must complete this table and turn it in with your final report. More } \\
\text { process at least } 4 \text { of the constraints shown above. Your final report should als } \\
\text { constraints were addressed in your project design and development. You may } \\
\text { existing list. }\end{array}$ & 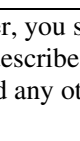 & includ & $\begin{array}{l}\text { he desi } \\
\text { (or mo } \\
\text { raint to }\end{array}$ & \\
\hline
\end{tabular}


Just as a quick side note, faculty do ensure that the complexity level of a given project is proportional to the class level, and the time allocated for it. Projects, many times, need to be reduced with respect to the initial student proposal. Curiously, students regularly return to their original (more complex) specifications and complete the project successfully. A collateral benefit of the laboratory intensive curriculum is that recruiting students becomes a much easier task, as typical engineering minded students enjoy the creative component in the classroom.

The four-year program culminates in the Capstone Design Class, a major design experience that mixes students of multidisciplinary backgrounds into large teams ( $7-12$ students) models the creation of new company. This class has a heavy technical component, but also addresses entrepreneurship, leadership, etc. The class is described in detail in Section IV.

Finally, the input from the faculty was used to determine the concentrations, or areas of specialization, the program would offer. Taking the advice from one of the advisory board members, we decided that we could not be everything to everyone, and as such created three areas of concentration: 1) microelectronics and VLSI, 2) signal processing and communication systems, and 3) power systems, aligning them with the expertise of the faculty.

The curriculum, thus, includes most of the components that the various constituencies stated were necessary for a $21^{\text {st }}$ century graduate, beyond the rigorous technical component: communication skills, entrepreneurship, initiative, leadership, system-level critical thinking, and a recognition of the continuous, self-learning engineers experience throughout their lives.

\section{Capstone Design Class}

This Capstone Design class is common with the Mechanical Engineering Technology program and, in compliance with University requirements, it is open to any student in the university, with the only prerequisite being senior level standing. In appearance, this class has very little practical use in the curriculum. However, in practice, it has been one of the biggest successes in the program, both in terms of student interest and in praise from the advisory board and employers. The class models the formation of a business based on a given product. Students must set up their own "company's" bylaws and executive hierarchy (e.g. CEO, CTO, etc.) in the first week of the quarter, while deciding on a given product the company will produce. In deciding on a final product, students must keep in mind that during the final week of the term a production line must be set up in which the product should be mass produced. The total number of finished products is variable depending of the total price of each individual unit, but it must be larger than 15. In other words, the product must be complex enough to meet minimum technical needs set by the instructor, but at the same time it should not be unfeasible for a team of students to "mass produce" in a week's time. It is required for students to do a short but realistic market study before choosing a particular product. Surveys of faculty, other students and community members are typically done during the product selection as a marketing study.

Budgetary requirements must be kept closely managed by students, as they are given a maximum amount to be spent, although donations from local industry are not included as expenditures in 
the final budget. ${ }^{2}$ Personal investments (up to a certain amount) are allowed. However, one of the requirements of the class is that, should they sell the product, they recoup all money used in the product development. In other words, if they build 15 chess clocks, with a total cost of $\$ 1500$, they should present marketing data that states that people are willing to buy chess clocks at $\$ 100$.

Typically students separate the work in the teams by their area of expertise. For example, a miniature basketball game in which a ball is projected through a hoop by means of a catapult system, the electrical engineering students designed and build the sensor system, counter, and digital score display, while the mechanical engineers were in charge of the catapult and frame.

The final portion of the class requires students to work with a team of Visual Communication Design (VCD) students, whose capstone project is made to overlap with the engineering class. The VCD students are in charge of their marketing campaign, making promotional materials such as business cards, envelope, company logo, website etc. A significant amount of communication is done between the two groups. One of the most important aspects of the class reported by students in their class evaluations is the steep learning curve incurred in communicating with people of different backgrounds

As a final side note, the Department of Business has learned of the continued success of the capstone class and has recently requested to work together with the Engineering \& Design Department to expose their students to the entrepreneurship involved in the class.

\section{Accreditation Preparation}

The Department has the great advantage of having a seasoned ABET evaluator among the faculty. Thus, as soon as the curriculum was established, preparations for ABET accreditation begun. While ABET does not grant accreditation visitations until after the first graduating class in any given program, the preparations started very early in the process. A set of clear program objectives and outcomes was drafted based on the vision of the Department. It is worth noting that an outcome is defined the set of skills students are supposed to have at the time of graduation. An objective, on the other hand, is extended to those skills within 3-5 years of graduation. Also in direct relation to these outcomes and objectives, a master course description (MCD) for each class was developed that includes both the topics to be covered by the class, the class delivery methodology (i.e. lecture, labs, etc.) and, most importantly a set of course learning objectives. Each course learning objective is matched to one or more ABET criteria. For example, the Electronics class has the following listed in its master course description:

\footnotetext{
${ }^{2}$ Faculty were torn about not including donations in the final budget. On the one hand in the real world there are no such as things are freebies. On the other, this concession encourages students to seek out industry "partners", thereby practicing communication skills and engaging in real networking. The latter argument won.
} 
Learning Objectives (and corresponding mapping to ABET Criteria 3): Upon completion of this course, students will be able to:

1. Explain semiconductor material properties (ABET 3a)

2. Apply the characteristics of diodes to create wave shaping circuits (rectifiers, clippers and clampers) (ABET 3a).

3. Apply the characteristics of the zener diode to the design of voltage regulator circuits (ABET $3 \mathrm{c}, 3 \mathrm{e})$.

4. Discuss and develop the parameters and characteristics of the ideal OA (ABET $3 a, 3 b$ ).

5. Analyze and design OA based circuits (ABET 3c, 3e).

6. Describe and analyze operation modes and characteristics of the MOSFET (ABET 3a).

7. Calculate the DC operating point of MOSFET circuits (ABET 3a).

8. Develop the small signal model of MOSFET devices (ABET 3a, 3j).

9. Analyze and design CS, CG, CD amplifier configurations (ABET 3c, 3e).

10. Use CAD tools such as SPICE to model, analyze, simulate, design and improve the functionality of basic semiconductor devices and circuits (ABET $3 \mathrm{~g}, 3 \mathrm{i}, 3 \mathrm{j}, 3 \mathrm{k}$ ).

The availability of a list like this for every course ensures that all ABET criteria are covered sufficiently throughout the program. Note that these lists were the result of the joint effort of faculty and advisory board members with expertise in each field, e.g. power experts drafted course learning objective of power courses, etc. Just as the program objectives and outcomes can be seen as the program's "constitution", these course learning objectives are a class' constitution as well. Not only does this ensure regularity in the contents taught, but it also ensures that the assessment system goes beyond individual faculty personal feeling on a given field. Ammending the program outcomes and objectives, as well as modifying the course learning objectives can only occur as a result of changes in the field, and/or observations from the different assessment techniques described below. Assessing outcomes and objectives was addressed in a different manner:

\section{i. Outcomes assessment}

Outcomes are the easiest to measure, as gathering data while students are still in the classroom is far easier than once they graduate. It was decided that assessment would be done by using an embedded course assessment tool that matches the program's outcomes to ABET criteria $3 \mathrm{a}-3 \mathrm{k}$. The tool, developed by the faculty, measures the achievement of individual course learning objectives and automatically assigns a related measurement, in a 4.0 scale, to the respective program outcome and ABET criteria [7]. For example, if course learning objectives 1 and 2 receive a "grade" of 3.2/4.0 and 3.6/4.0, respectively, ABET criteria 3a is said to have been met with a 3.4/4.0 grade. Data from all courses is put together, compiled and the results analyzed by the faculty as a group. As class grades are not recommended as the only method to measure the achievement of ABET outcomes, several other mechanisms have been used, such as student focus groups, employer data from internship, student portfolios, exit surveys, etc. Moreover, three samples of every test, homework, quiz, project report, etc. have been kept thoroughly. A room in the building has been reserved exclusively for the use of ABET data, and all copies of student work are kept there.

While assessing the achievement of program outcomes for any particular year is not necessarily difficult to do, the process to ensure continuous improvement, as mandated by 


\begin{abstract}
ABET is a different story. In the Department the continuous improvement loop is initiated by all faculty analyzing the reports from each individual class on a regular basis, providing a first layer of comments on suggested modifications to a given class. Content changes deemed necessary by the faculty are reported to the Advisory Board in an annual meeting held at the end of the school year. Note that the Advisory Board has student participation, thereby ensuring input from this constituency. A change in class content needs to be approved by the Advisory Board. Moreover, if the Advisory Board considers all changes significant enough, it may mandate a change to one or more program outcomes.
\end{abstract}

\title{
ii. Objectives assessment
}

As expected, the assessment of program objectives is a much more complicated process. Gathering of data requires tracking alumni and requesting input both from them and their employers. No data has been obtained yet, as our alumni have not been out of school 3-5 years yet. However, accreditation depends not necessarily on data, but on a process being established to measure the assessment of objectives and to ensure the assessment loop is closed by using the method to address problems observed in the data. Data to be gathered toward the assessment of achievement of program objectives include focus groups and surveys by employers and surveys to alumni. The data gathered is analyzed in the same manner as described above for outcomes assessment. Figure 2 illustrates the continuous improvement process.

One observation that may be worth stating is that ABET assessment need not be a burden in the long term. While the initial effort may be significant to set up a system by which accreditation is done, once the system is in place assessment becomes merely part of the typical teaching load. Note that assessment and continuous improvement must be done regularly and on a yearly basis, and as such should not be left to a last minute, procrastinatory effort. The program was granted ABET accreditation during the summer of 2008 . 
Figure 2. Continuous improvement cycle for program outcomes/objectives

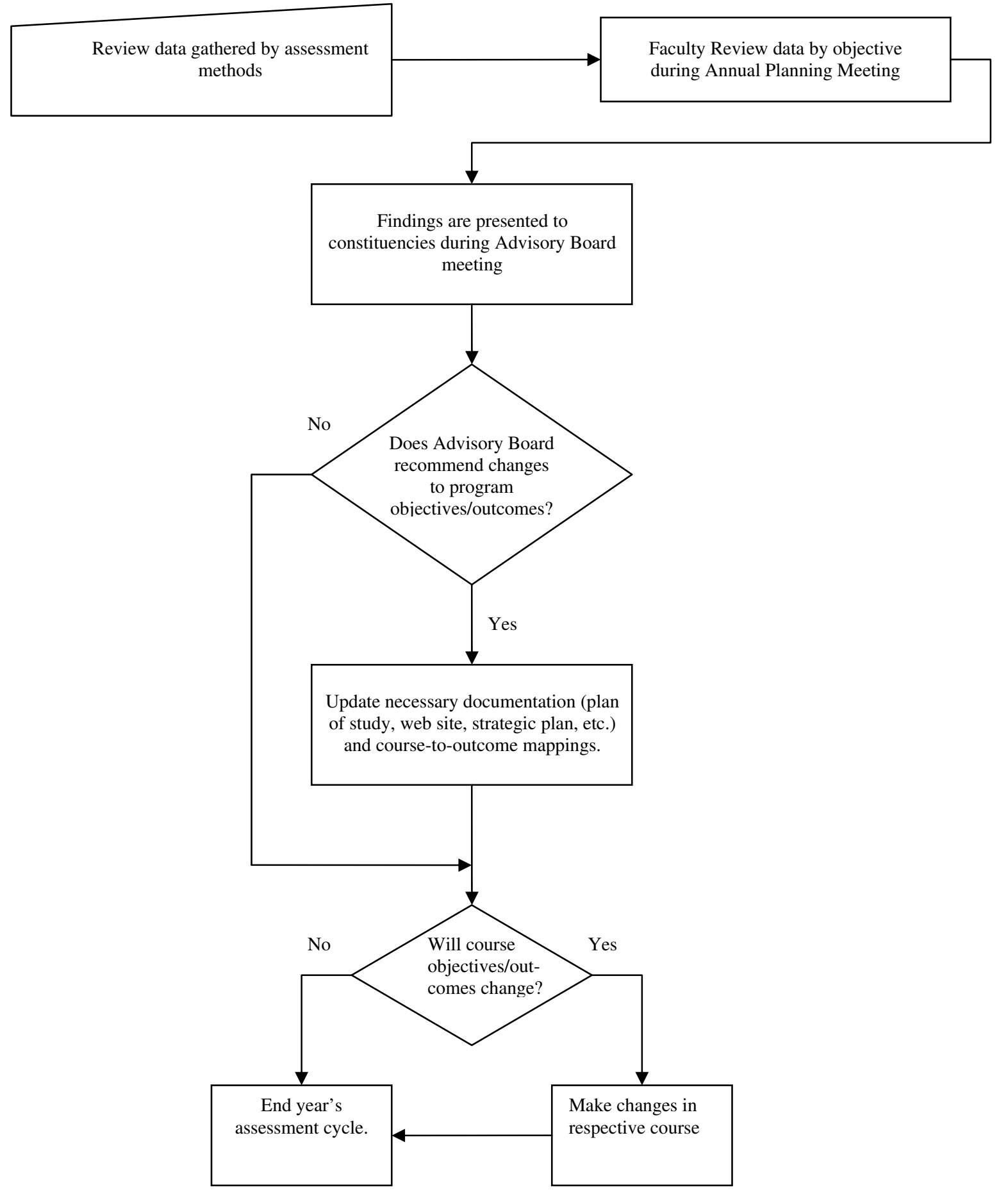




\section{Conclusions}

This paper described the history and process of opening an electrical engineering program at EWU, a regional comprehensive university previously offering only Engineering Technology degrees. Several problems were tackled in the process, and each addresses issues that should be considered by other universities intending finding themselves in a similar position. First, be ready to engage in an incredible amount of work, typically swimming against the current inside the institution itself, against other institutions, and against the State's Higher Education Coordinating Board. Second, play to your strengths and do not try to be everything to everybody. The faculty expertise should be maximized by concentrating in areas that can be taught with no further resources being allocated into the program, as typically resources are scarce. Third, ensure program outcomes and objectives are matched with the vision and strategic plan of the Department, College and, hopefully, University. This has the added benefit that in times of economic frailty those programs closely aligned with the mission and vision of the University will receive preferential treatment. Fourth, ensure that a vision of what the institution's graduates' skill set is expected to be is clear during the design of the curriculum. Traits that differentiate a graduate of the institution to graduates of other institutions will be always present in a (hopefully happy) employer's mind during the hiring process. Fifth, seek an active advisory board and involve its members in every step of the way. There is no better help than that obtained from future employers. Sixth, start preparing for ABET accreditation as early as possible, and once started keep the ball rolling...forever! The process of continuous improvement required by ABET can be seen as a hassle and it does take a significant amount of time, but it really does help the program in the long run. If done in a continuous basis it rapidly becomes part of the habitual teaching process and will no longer be seen as an extra load on the (surely already overloaded) faculty. Seventh, support from industry is very useful. In our case it came in form of equipment and other donations, but it also has provided students with internships and, ultimately, jobs. Last, although by no means least, enlisting the support of the University administration on day one is not only useful, but critical, as navigating through the bureaucracy is not a light task.

\section{Bibliography}

[1] "Criteria for Accrediting Engineering Programs" Effective for the 2007-2008 accreditation cycle, ABET, Engineering Accreditation Commission (EAC), 11/15/06, ABET Inc., 111 Market Place, Suite 1050, Baltimore, MD 21202.

[2] T.Currin and T. Zeigler, "Building and Construction Engineering Program," in the Proceedings of the 2007 Annual Conference of the American Society of Engineering Education, Hololulu, HI, June 2007.

[3] Wainer da Silveira e Silva, "Creating a New Engineering Program in a Developing Country," in the Proceedings of The 2006 IJME - International Conference on Engineering \& Technology: ResearchEducation-Entrepreneurship Conference, Union Township, NJ ,October, 2006.

[4] R. Prins, O. Pierrakos, E. Pappas, and R. Kander, "Work in Progress - A Freshman Engineering CourseDesigned to Convey the Essence of the Engineering Program at James Madison University," in the Proceedings of the 38th ASEE/IEEE Frontiers in Education Conference, October 22 - 25, 2008, Saratoga Springs, NY.

[5] Kander, R, G, "Building a New Kind of Engineering Degree at James Madison University", in the Proceedings of the 115th ASEE Conference, Pittsburgh, PA, June 22-25, 2008. 
[6] T. Abdel-Salam, K. Williamson, and P. Kauffman, "Using the Web to invite the local community into the engineering classroom," in the Proceedings of the 35th Annual Conference Frontiers in Education, 2005.

[7] E. Rodriguez-Marek, M.S. Koh, and C. Talarico, "Connecting the dots in assessment: From course student learning objectives to educational program outcomes to ABET assessment", in the Proc. of the 2008 ASEE annual Conf. and Exposition, Pittsburgh, PA, Jun. 2008 